\title{
Structure of Active Sites of Fe-N-C Nano-Catalysts for Alkaline Exchange Membrane Fuel Cells
}

\author{
Hirofumi Kishi ${ }^{1}$, Tomokazu Sakamoto ${ }^{1}$, Koichiro Asazawa ${ }^{1, *}$, Susumu Yamaguchi ${ }^{1}$, \\ Takeshi Kato ${ }^{1}$, Barr Zulevi ${ }^{2}$, Alexey Serov ${ }^{2}$, Kateryna Artyushkova ${ }^{3}$, Plamen Atanassov ${ }^{3}$, \\ Daiju Matsumura ${ }^{4}$, Kazuhisa Tamura ${ }^{4}$, Yasuo Nishihata ${ }^{4}$ and Hirohisa Tanaka ${ }^{5}$
}

1 Advanced R\&D Department, Daihatsu Motor Co. Ltd., 3000 Yamanoue, Ryuo, Gamo, Shiga 520-2593, Japan; Hirofumi_Kishi@dk.daihatsu.co.jp (H.K.); Tomokazu_Sakamoto@dk.daihatsu.co.jp (T.S.); Susumu_Yamaguchi@dk.daihatsu.co.jp (S.Y.); Takeshi_Katou@dk.daihatsu.co.jp (T.K.)

2 Pajarito Powder Limited Liability Company (LLC), 3600 Osuna Rd NE, Suite 309, Albuquerque, NM 87102, USA; bhalevi@pajaritopowder.com (B.Z.); aserov@pajaritopowder.com (A.S.)

3 Department of Chemical \& Biological Engineering, Center for Micro-Engineered Materials (CMEM), University of New Mexico, Albuquerque, NM 87131, USA; kartyush@unm.edu (K.A.); plamen@unm.edu (P.A.)

4 Quantum Beam Science Center, Japan Atomic Energy Agency, 1-1-1, Koto, Sayo, Hyogo 679-5148, Japan; daiju@spring8.or.jp (D.M.); tkazu@spring8.or.jp (K.T.); yasuon@spring8.or.jp (Y.N.)

5 Department of Nanotechnology for Sustainable Energy, School of Science and Technology, Kwansei Gakuin University, 2-1 Gakuen, Sanda, Hyogo 669-1337, Japan; hirohisa.tanaka@kwansei.ac.jp

* Correspondence: koichiro_asazawa@dk.daihatsu.co.jp; Tel.: +81-748-57-1685

Received: 19 October 2018; Accepted: 16 November 2018; Published: 22 November 2018

\begin{abstract}
Platinum group metal-free (PGM-free) catalysts based on transition metal-nitrogen-carbon nanomaterials have been studied by a combination of ex situ and in situ synchrotron X-ray spectroscopy techniques; high-resolution Transmission Electron Microscope (TEM); Mößbauer spectroscopy combined with electrochemical methods and Density Functional Theory (DFT) modeling/theoretical approaches. The main objective of this study was to correlate the $\mathrm{HO}_{2}{ }^{-}$ generation with the chemical nature and surface availability of active sites in iron-nitrogen-carbon (Fe-N-C) catalysts derived by sacrificial support method (SSM). These nanomaterials present a carbonaceous matrix with nitrogen-doped sites and atomically dispersed and; in some cases; iron and nanoparticles embedded in the carbonaceous matrix. Fe-N-C oxygen reduction reaction electrocatalysts were synthesized by varying several synthetic parameters to obtain nanomaterials with different composition and morphology. Combining spectroscopy, microscopy and electrochemical reactivity allowed the building of structure-to-properties correlations which demonstrate the contributions of these moieties to the catalyst activity, and mechanistically assign the active sites to individual reaction steps. Associated with $\mathrm{Fe}-\mathrm{N}_{\mathrm{x}}$ motive and the presence of $\mathrm{Fe}$ metallic particles in the electrocatalysts showed the clear differences in the variation of composition; processing and treatment conditions of SSM. From the results of material characterization; catalytic activity and theoretical studies; Fe metallic particles (coated with carbon) are main contributors into the $\mathrm{HO}_{2}{ }^{-}$generation.
\end{abstract}

Keywords: anion exchange membrane fuel cells (AEMFCs); iron-nitrogen-carbon electrocatalysts (Fe-N-C); $\mathrm{HO}_{2}{ }^{-}$generation; oxygen reduction reaction 


\section{Introduction}

Platinum has a limited availability on Earth, and its substitution with a platinum group metal-free (PGM-free) electrocatalyst is needed in order for the fuel cell to become feasible and widely spread technology [1-3].

Among several classes of PGM-free catalysts, transition metal-nitrogen-carbon (M-N-C) nanomaterials, where the transition metal $(\mathrm{M})$ is usually $\mathrm{Fe}, \mathrm{Ni}, \mathrm{Co}$ (or few others) are most often studied and discussed. M-N-C nanomaterials are highly active electrocatalysts for oxygen reduction reaction (ORR). An iron-nitrogen-carbon electrocatalyst (Fe-N-C) has attracted attention due to its highest ORR activity among the other M-N-C electrocatalysts and demonstrated multiple synthesis protocols to yield desired nanomaterial. Fe-N-C have been employed in experimental proton exchange membrane fuel cells (PEMFC) and have demonstrated promise, while still being much inferior to PGM catalysts [4]. In contrast, in alkaline media M-N-C demonstrate performance at par with PGM, as such find applications as cathode materials in Anion Exchange Membrane Fuel Cells (AEMFCs) [5].

In general, Fe-N-Cs are synthesized through pyrolysis of an N-containing organic precursor, serving as a source of the carbonaceous matrix and a transition metal salt as a source of the metal-containing moieties in the final nanomaterial [6]. Often, the metal is present in the precursor compound, as in metal organic frameworks (MOF) or is introduced in a specific stage of the catalyst preparation [7-9]. Substantial efforts have been made towards identifying the structure of the active sites in M-N-C nanomaterials. Current understanding of the M-N-C (and specifically Fe-N-C) catalyst structure involves two central hypotheses: (i) transition metal is atomically dispersed and is built into $\mathrm{N}$-containing carbonaceous matrix and is the site on which di-oxygen binds prior to electro-reduction steps $[10,11]$, and (ii) transition metal form nano-particles of ether reduced metal or metal carbide, which are immersed in carbonaceous matrix and induce ORR catalytic properties onto that matrix, without directly participating in the reaction [12]. Explicit understanding of the chemical structure of the active sites in M-N-C nanomaterials is additionally obscured by the fact that several Fe-containing and $\mathrm{N}$-containing moieties are catalytically active in various individual steps of ORR [13]. This interplay between multiplicity of the chemical structure of the individual active sites and their participation in reaction mechanism, especially in the generation of intermediate $\mathrm{HO}_{2}{ }^{-}$, have yet to be revealed in full.

Under alkaline conditions, the kinetics of the Oxygen Reduction Reaction (ORR) on the cathode is enhanced leading to improved overall fuel cell efficiency. Anion exchange membrane fuel cells (AEMFCs) with an alkaline liquid electrolyte such as $\mathrm{KOH}$ (aq) are the best performing of all known conventional hydrogen oxygen fuel cell types. The application of alkaline conditions at the electrodes opens the potential to use a range of low-cost PGM-free catalysts. In order to enable liquid electrolyte-free AEMFCs, a number of groups have begun research efforts devoted to fabrication and engineering of anion-exchange membranes and ionomer solutions [14-20]. Also, there are incentives to develop novel materials for AEMFC systems that have the potential to alleviate or eliminate the technical issues associated with liquid electrolyte systems. This may include the use of a much more diverse selection of potential fuels that are thermodynamically favorable in alkaline media.

As one of the most promising ORR electrocatalysts for AEMFC, transition metal-nitrogen-carbon catalysts (M-N-C) have been intensively studied [21]. The performance of these catalysts is remarkably better in a direct hydrazine fuel (DHFC) cell in comparison with a polymer electrolyte fuel cell reaching a power density of $500 \mathrm{~mW} / \mathrm{cm}^{2}[1,21,22]$. Jasinski was the first to show the potential of utilizing a transition metal macrocycle compounds for alkaline oxygen electroreduction [23]. In order for the M-N-C catalysts to achieve their highest overall performance, they must have a well-developed morphology and high density of active sites [24-26].

For over a decade, the University of New Mexico has been developing an original synthetic method for M-N-C catalysts preparation called the Sacrificial Support Method (SSM) [4,27]. An industrial application for the SSM was successfully brought onto the catalyst market by Pajarito Powder under the trademarked name VariPore ${ }^{\mathrm{TM}}$ [28]. The SSM synthesis produces material with multiple controlled surface defects within a carbonaceous network and an internal network of 
connected pores with adjustable pore size distribution (PSD). The key chemical features of these electrocatalysts result in high activity and excellent stability. Additionally, it is significant that the formulations, processing and treatment conditions of SSM can be optimized for the best ORR performance at AEMFCs conditions.

To rationally design active and durable electrocatalysts for AEMFCs, the mechanism and the nature active site of ORR in alkaline conditions need to be identified. Especially, it is crucially required to reveal the mechanism of $\mathrm{HO}_{2}{ }^{-}$species generation because $\mathrm{HO}_{2}{ }^{-}$is a source of $\mathrm{OH}$ radical [29] which decreases the longevity of anion-exchange membranes and ionomer dispersions.

To reveal the mechanism of $\mathrm{HO}_{2}{ }^{-}$generation, $\mathrm{Fe}-\mathrm{N}-\mathrm{C}$ ORR electrocatalysts synthesized with variation of several parameters were analyzed by synchrotron X-ray radiation to build structure-to-properties correlations on the basis of our previous works [30-33]. The structure of electrocatalysts, which is associated with Fe- $\mathrm{N}_{\mathrm{x}}$ motive and the presence of Fe metallic particle showed the clear difference in the variation of composition, processing and treatment conditions of SSM. From the results of material characterization X-ray Absorption Fine Structure (XAFS), Scanning Transmission Electron Microscope (STEM), catalytic activity test (Rotating Ring Disk Electrode, RRDE) and theoretical studies (DFT calculation), it was indisputably shown that Fe metallic particle (coated with carbon) are main contributors to the $\mathrm{HO}_{2}{ }^{-}$generation.

In parallel to the analysis of the mechanism of $\mathrm{HO}_{2}{ }^{-}$generation, we performed Mößbauer spectroscopy measurements and in situ XAFS analysis of the iron species to derive a guideline for the design of highly active ORR catalysts.

\section{Materials and Methods}

\subsection{Catalyst Preparation}

The catalysts were synthesized by modified SSM [30,31]. Iron nitrate $\left(2.5 \mathrm{~g}, \mathrm{Fe}\left(\mathrm{NO}_{3}\right)_{3} \cdot 9 \mathrm{H}_{2} \mathrm{O}\right.$, Sigma Aldrich) was mechanically mixed with $25 \mathrm{~g}$ of the nitrogen-rich organic precursors (Nicarbazin and Pipemidic acid) and $10 \mathrm{~g}$ of LM-150 fumed silica (Cabot Cab-O-sil ${ }^{\circledR}$, surface area $\sim 150 \mathrm{~m}^{2} / \mathrm{g}$ ). The pre-mixed material was loaded into a $100 \mathrm{~mL}$ agate ball-mill jar with 16 agate balls (diameter $1 \mathrm{~cm}$ ). The mixture was subjected to ball-milling at $450 \mathrm{rpm}$ for $1 \mathrm{~h}$. The homogeneous powder was pyrolyzed at $\mathrm{T}=950^{\circ} \mathrm{C}, \mathrm{t}=30 \mathrm{~min}$ in the flow of Ultra High Purity (UHP) Nitrogen, $100 \mathrm{ccm}$. After heat treatment, silica was removed by $20 \mathrm{wt}$ \% HF (1st acid treatment), followed by washing with DI water until neutral $\mathrm{pH}$ was reached. The obtained powder was dried overnight at $\mathrm{T}=85^{\circ} \mathrm{C}$. In order to remove Fe metallic particles, the catalysts were acid treated with $1 \mathrm{M} \mathrm{HNO}_{3}$ (2nd acid treatment). The abbreviations of each catalyst sample are shown in Table 1 together with the precursor and acid treatment history.

Table 1. Synthesized Fe-N-C electrocatalysts.

\begin{tabular}{cccc}
\hline Catalyst (Abbreviation) & Precursor & 1st Acid Treatment & 2nd Acid Treatment \\
\hline NCB & Nicarbazin & $20 \mathrm{wt} . \% \mathrm{HF}$ & - \\
NCB-N & Nicarbazin & $20 \mathrm{wt.} \% \mathrm{HF}$ & $1 \mathrm{M} \mathrm{HNO}_{3}$ \\
PPM-N & Pipemidic acid & $20 \mathrm{wt} \% \mathrm{HF}$ & $1 \mathrm{M} \mathrm{HNO}_{3}$ \\
\hline
\end{tabular}

\subsection{XAFS Data Collection and Analysis}

X-ray absorption fine structure (XAFS) measurements were carried out at line BL14B2 line of SPring-8 as in our previous work [32,33]. During in-situ XAFS analysis, potential was set at $0.25 \mathrm{~V}, 0 \mathrm{~V}$, $-0.20 \mathrm{~V},-0.40 \mathrm{~V},-0.60 \mathrm{~V},-0.75 \mathrm{~V}$ and $-0.90 \mathrm{~V}$ vs. $\mathrm{Hg} / \mathrm{HgO}(1.174 \mathrm{~V}, 0.924 \mathrm{~V}, 0.724 \mathrm{~V}, 0.524 \mathrm{~V}, 0.324 \mathrm{~V}$, $0.174 \mathrm{~V}$ and $0.024 \mathrm{~V}$ vs. RHE). XAFS data processing was done using EXAFS analysis software (Ifeffit; University of Chicago, Chicago, IL, USA) for fitting. 


\subsection{Rotating Ring-Disk Electrode (RRDE) Preparation and Testing}

The catalyst layer setup to the disk electrode and electrochemical measurement has been done as our previous work [32]. The ratio of $\mathrm{HO}_{2}{ }^{-}$generation was calculated using Equation (1).

$$
\begin{aligned}
\mathrm{P}\left(\mathrm{HO}_{2}{ }^{-}\right)(\%) & =2 \times \mathrm{I}_{\mathrm{r}} /\left(\mathrm{N} \times \mathrm{I}_{\mathrm{d}}+\mathrm{I}_{\mathrm{r}}\right) \times 100 \\
(\mathrm{~N} & =0.38 \text { in this work })
\end{aligned}
$$

\subsection{STEM Analysis}

Scanning Transmission Electron Microscope (STEM) and STEM-EDS (JEM-ARM200F, Japan Electron Optics Laboratory Company Limited; Tokyo, Japan) with the voltage acceleration of $200 \mathrm{kV}$ were performed to analyze catalyst morphology and composition.

\subsection{HAXPES Analysis}

Hard X-ray Photo Electron Spectroscopy (HAXPES) measurements were carried out at BL46XU and BL47XU of SPring-8; Hyogo, Japan. The source X-ray energy was 7940 eV. Fe2p spectra were acquired. Spectra were charge calibrated to the binding energy for Au standard plate of $84 \mathrm{eV}$ (Au4f).

\section{6. ${ }^{57} \mathrm{Fe}$ Mößbauer Spectroscopy}

Mößbauer measurements were made to characterize the iron compounds within each catalyst. The spectra were recorded at room temperature with a CMCA-550 (WissEl; Starnberg, Germany) equipped with a constant electronic drive system with a triangular reference waveform (Halder Electronics). A ${ }^{57}$ Co source was used, and the velocity scale and isomer shift $\delta$ iso were calibrated with natural iron ( $\alpha$-Fe-foil, $25 \mathrm{~mm}$ thick, 99.99\% purity). An assignment of the iron species was made by a comparison of the Mößbauer parameters to literature data [34,35].

\subsection{Computational Study}

Calculations were done by using the spin-polarized DFT under Kohn-Sham formalism, implemented in Quantum Espresso [36]. Projector augmented wave (PAW) was used to represent core electrons [36]. Exchange-correlation energy functional was expressed by using generalized gradient approximation by Perdew-Burke-Ernzerhoff (GGA-PBE) [37]. Plane-wave basis sets were used with energy cut-off of $400 \mathrm{eV}$. The integration on Brillouin zone is done in $4 \times 4 \times 1$ grid. 2 type surfaces are modeled to evaluate $\mathrm{HO}_{2}{ }^{-}$generating process. Two type surfaces were (a) Fe coated with carbon using graphene on 4 layers of $\mathrm{Fe}(001)$ and (b) graphene as a reference. Adsorption molecule, graphene and upper half layers of $\mathrm{Fe}(001)$ were relaxed and lower half layers of $\mathrm{Fe}(001)$ were fixed to evaluate the most stable structure of the adsorbed molecules. For calculations of $\mathrm{O}_{2}{ }^{2-}$ adsorption as an initial state [38], the total charge in the unit cell was -2 (two additional electrons).

\section{Results}

Figure 1 shows Fourier-transforms of the Fe K-edge extended X-ray absorption fine structure (ex-situ EXAFS) spectra for three samples of electrocatalysts. Synthesized Fe-N-C electrocatalysts have two peaks. The first nearest neighbor peak around $1.6 \AA$ is assigned to the Fe- $\mathrm{N}_{\mathrm{x}}$ structure [39]. The second peak around $2.2 \AA$ is assigned to Fe-Fe originating from Fe metallic particles. NCB represents the peak of Fe-Fe higher than NCB-N and PPM-N, indicating that acid treatment with $\mathrm{HNO}_{3}$ facilitates removal of Fe metallic particles. PPM-N represents the lowest peak of Fe-Fe and a higher peak of Fe- $\mathrm{N}_{\mathrm{x}}$ rather than the others, indicating that using PIPEM as precursor reduces the amount of Fe metallic particles and increases the amount of Fe- $\mathrm{N}_{\mathrm{x}}$ structures. To reveal the relationship between the structure of Fe-N-C electrocatalysts and ORR activity (Equations (2) and (3)), RRDE analysis were done. 
Dual ORR reactions consist of the following two reactions:

$$
\begin{gathered}
\mathrm{O}_{2}+\mathrm{H}_{2} \mathrm{O}+2 \mathrm{e}^{-} \rightarrow \mathrm{HO}_{2}^{-}+\mathrm{OH}^{-}\left(\mathrm{E}_{0}=+0.761 \mathrm{~V} \text { vs. } \mathrm{RHE}, \mathrm{pH}=14\right) \\
\mathrm{HO}_{2}{ }^{-}+\mathrm{H}_{2} \mathrm{O}+2 \mathrm{e}^{-} \rightarrow 3 \mathrm{OH}^{-}\left(\mathrm{E}_{0}=+1.693 \mathrm{~V} \text { vs. } \mathrm{RHE}, \mathrm{pH}=14\right)
\end{gathered}
$$

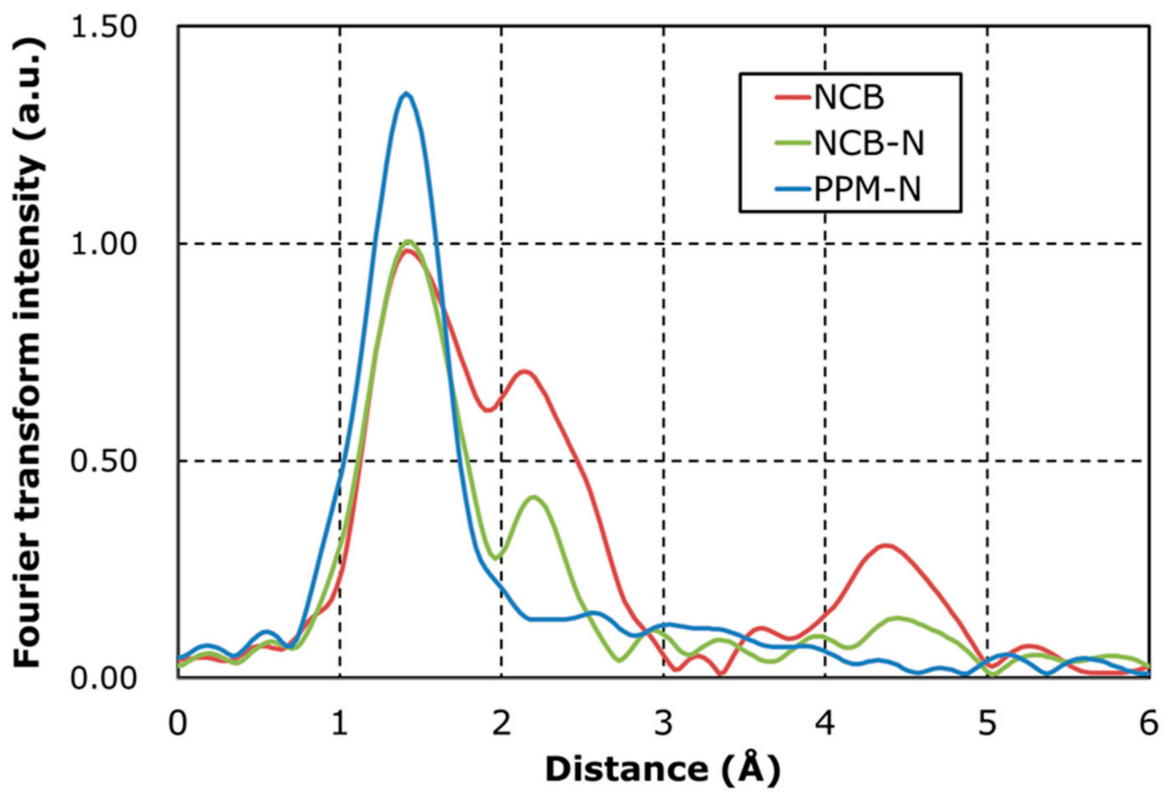

Figure 1. Radial structure function around Fe, calculated from the Fourier-transforms of the Fe K-edge extended X-ray absorption fine structure (EXAFS) spectra of NCB, NCB-N, and PPM-N.

Figure 2 and Table 2 show a comparison of RRDE results. NCB produces high amounts of $\mathrm{HO}_{2}{ }^{-}$ and results in low kinetic currents and onset/half wave potential. It suggests that the process to generate $\mathrm{HO}_{2}{ }^{-}$via Equation (2) is enhanced and $\mathrm{HO}_{2}{ }^{-}$reduction via Equation (3) does not progress. On the other hands, PPM-N produces low amounts of $\mathrm{HO}_{2}{ }^{-}$and results in high kinetic currents and onset/half wave potential because some of the remaining Fe particles are removed by the second leach of $\mathrm{HNO}_{3}$. This suggests that the reduction of $\mathrm{HO}_{2}{ }^{-}$via Equation (3) is more active for PPM-N than for NCB. NCB-N is in between NCB and PPM-C. To discuss the effect of Fe-N-C structures (from Figure 1 and Table 3) to $\mathrm{HO}_{2}{ }^{-}$generation, the relationship between $\left.\mathrm{P}_{\left(\mathrm{HO}_{2}\right.}{ }^{-}\right)$and the ratio of Fe

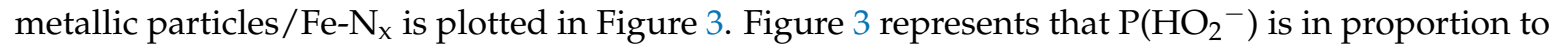
the ratio of Fe metallic particles $/ \mathrm{Fe}-\mathrm{N}_{\mathrm{x}}$. From this result, it is hypothesized that Fe metallic particles enhance $\mathrm{HO}_{2}{ }^{-}$generation represented by Equation (2). To confirm this hypothesis, it is necessary to discuss ORR mechanism on the surface of Fe metallic particles. STEM analysis has been done to investigate surface structure of Fe metallic particles. 


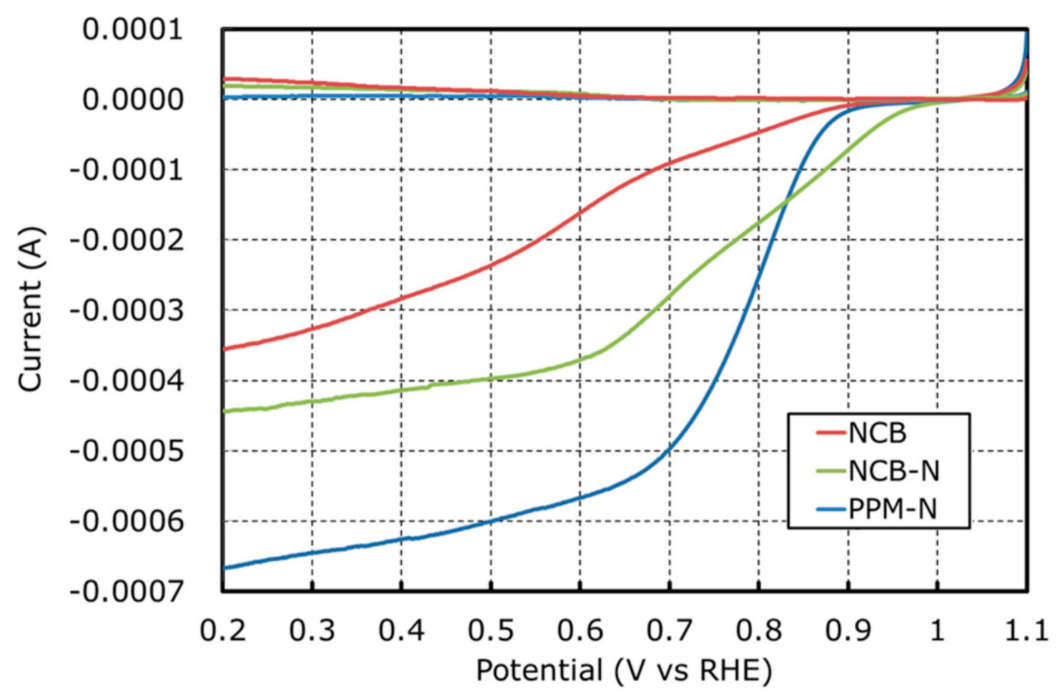

Figure 2. Voltammograms on NCB, NCB-N, and PPM-N of oxygen reduction reaction with rotating ring-disk electrode in $1.0 \mathrm{M} \mathrm{KOH}$ at room temperature.

Table 2. Electrochemical performance of NCB, NCB-N, and PPM-N using RRDE.

\begin{tabular}{ccccc}
\hline Catalyst & $\begin{array}{c}\mathbf{P}\left(\mathrm{HO}_{\mathbf{2}}{ }^{-}\right) \\
\mathbf{N}=\mathbf{0 . 3 8}\end{array}$ & $\begin{array}{c}\mathbf{I}_{\mathbf{d}}(\mathbf{m A}) @ \mathbf{0 . 2} \mathbf{~ V} \\
\text { vs. RHE }\end{array}$ & $\begin{array}{c}\text { Onset Potential (V) } \\
\text { vs. RHE }\end{array}$ & $\begin{array}{c}\text { Half Wave Potential (V) } \\
\text { vs. RHE }\end{array}$ \\
\hline NCB & 44.6 & -0.35 & 1.01 & 0.57 \\
NCB-N & 28.6 & -0.44 & 1.04 & 0.74 \\
PPM-N & 8.4 & -0.67 & 1.04 & 0.78 \\
\hline
\end{tabular}

Table 3. Ratio of $\mathrm{Fe}-\mathrm{Fe} / \mathrm{Fe}-\mathrm{N}_{\mathrm{x}}$ which is calculated from EXAFS fitting.

\begin{tabular}{cccc}
\hline Catalyst & Fe-N $_{\mathbf{x}}$ (Area) & Fe-Fe (Area) & Fe-Fe/Fe-Nx (ratio) \\
\hline NCB & 0.68 & 0.53 & 0.78 \\
NCB-N & 0.65 & 0.24 & 0.37 \\
PPM-N & 0.81 & 0.09 & 0.11 \\
\hline
\end{tabular}

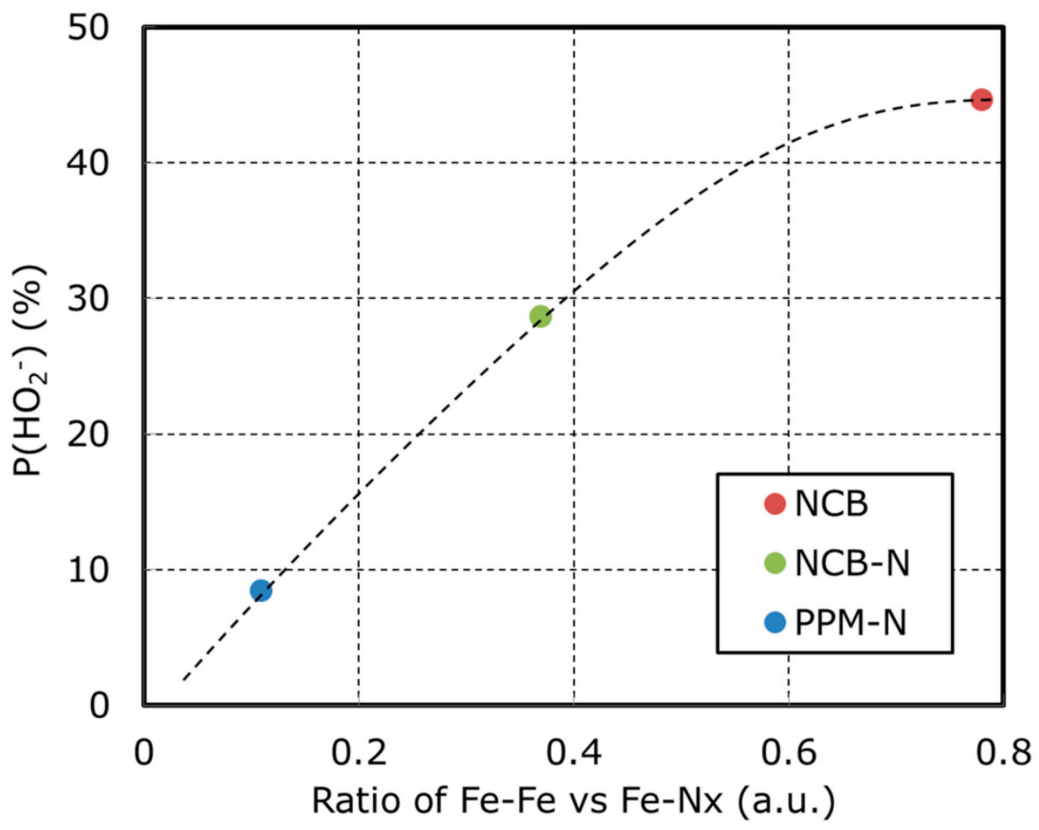

Figure 3. Voltammograms on NCB, NCB-N, and PPM-N of oxygen reduction reaction with rotating ring-disk electrode in $1.0 \mathrm{M} \mathrm{KOH}$ at room temperature. 
Figure 4 shows HAADF-STEM images and EDS mapping images of Fe for NCB, which represents the high amount of Fe metallic particles, and PPM-C as a reference. The results presented on Figure 4 represent good agreement with the results of EXAFS in Figure 1. Aggregated Fe metallic particles from 10 to $100 \mathrm{~nm}$ were observed in NCB (Figure 4a). Atomically distributed Fe, which was assigned as Fe- $N_{x}$, was observed in PPM-N (Figure $4 b$ ).
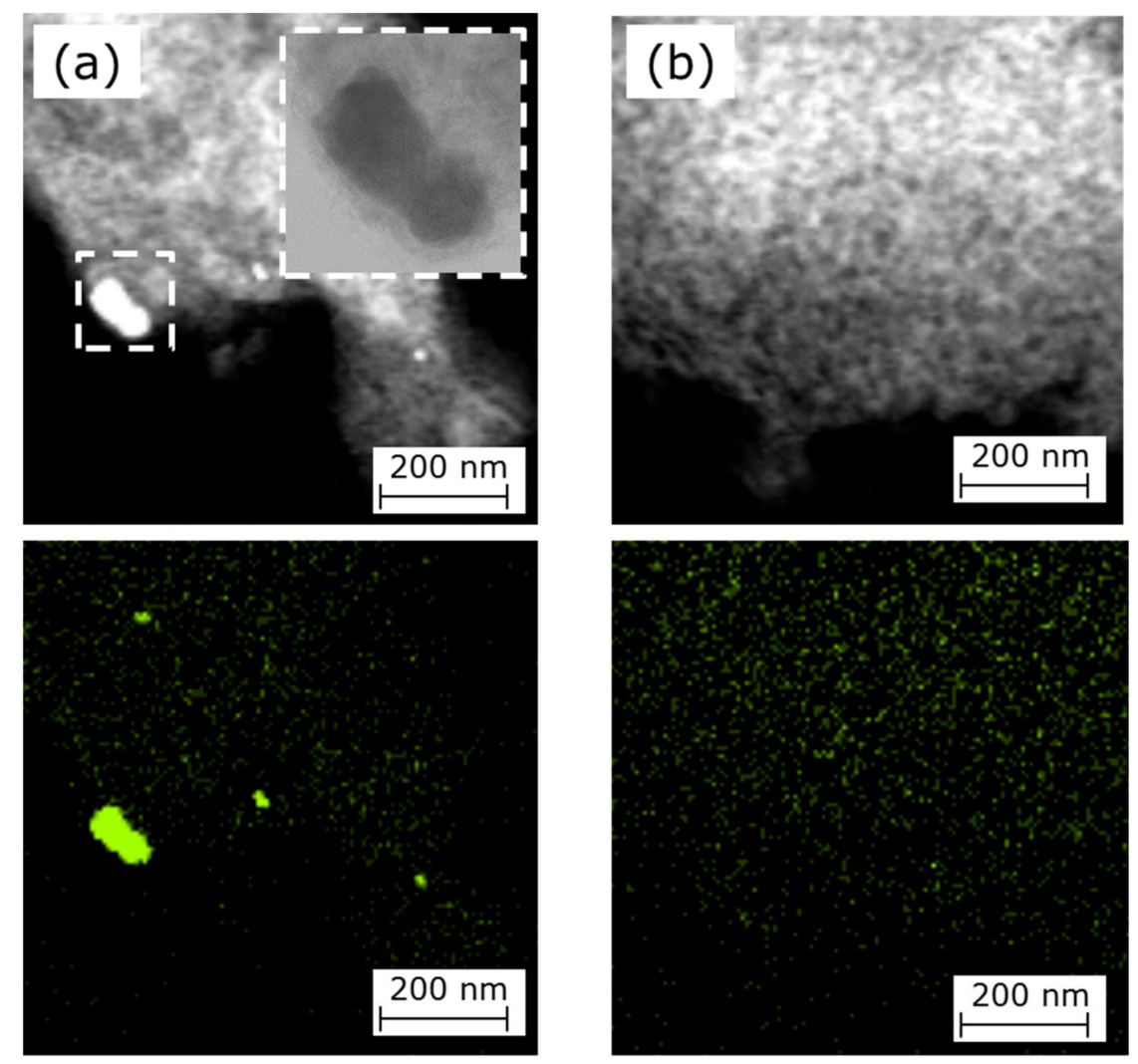

Figure 4. HAADF-STEM images and EDS mapping images of Fe, (a) NCB and (b) PPM-N.

In Figure 5, HAXPES shows the difference in amount of Fe metallic particles between NCB and PPM-N. These results also represent good agreement with the results of EXAFS in Figure 1 and HAADF-STEM in Figure 4.

Additionally, Figure 4a shows that Fe metallic particles were coated with a carbon layer. It is well known that carbon in alkaline condition is a strong $\mathrm{HO}_{2}{ }^{-}$generator [40]. Therefore, it is assumed that $\mathrm{HO}_{2}{ }^{-}$generation by carbon is enhanced by Fe metallic particle substrate. To investigate the interaction between Fe metallic particle substrate and carbon overlay, theoretical studies (DFT calculation) were done. Figure 6 presents the energy diagrams for the reaction on carbon (graphene) with Fe substrate (Fe(001) slab [41]) and on only carbon as a reference. It is well known that the edge structure of carbon enhances $\mathrm{HO}_{2}{ }^{-}$generation rather than terrace structure [42]. We assumed that the effect of Fe substrate would be present on the terrace but not on the edge. Hence DFT calculations were done based on graphene (as terrace carbon) on $\mathrm{Fe}(001)$ slab.

In this computational part, we focused on the calculation of the energy diagrams of the following reactions [32,39]:

$$
\begin{gathered}
\mathrm{O}_{2}+\mathrm{H}_{2} \mathrm{O}+2 \mathrm{e}^{-} \rightarrow{ }^{*} \mathrm{O}_{2}{ }^{2-}+\mathrm{H}_{2} \mathrm{O}: \mathrm{O}_{2} \text { adsorption } \\
{ }^{*} \mathrm{O}_{2}{ }^{2-}+\mathrm{H}_{2} \mathrm{O} \rightarrow{ }^{*}\left(\mathrm{O}_{2}+\mathrm{H}_{2} \mathrm{O}\right)^{2-}: \mathrm{H}_{2} \mathrm{O} \text { adsorption } \\
{ }^{*}\left(\mathrm{O}_{2}+\mathrm{H}_{2} \mathrm{O}\right)^{2-} \rightarrow{ }^{*} \mathrm{HO}_{2}{ }^{-}+\mathrm{OH}^{-}: \mathrm{HO}_{2}{ }^{-} \text {formation } \\
{ }^{*} \mathrm{HO}_{2}{ }^{-}+\mathrm{OH}^{-} \rightarrow{ }^{*} \mathrm{O}^{-}+2 \mathrm{OH}^{-}: \mathrm{HO}_{2}{ }^{-} \text {reduction }
\end{gathered}
$$




$$
{ }^{*} \mathrm{HO}_{2}{ }^{-}+\mathrm{OH}^{-} \rightarrow \mathrm{HO}_{2}{ }^{-}+\mathrm{OH}^{-}: \mathrm{HO}_{2}{ }^{-} \text {dissociation }
$$

* represents the adsorbed $\mathrm{X}$ molecule on the surfaces. We compared the energy diagram on graphene with $\mathrm{Fe}(001)$ and graphene. By making such comparisons, we could observe the possible rate-limiting step for $\mathrm{HO}_{2}{ }^{-}$generation on each surface.

In the case of graphene, the step of $\mathrm{O}_{2}$ adsorption (Equation (4)) required high energy as shown in Figure 6. This indicates that graphene without Fe metallic particle substrate was not so active for $\mathrm{HO}_{2}{ }^{-}$or $\mathrm{OH}^{-}$generation.

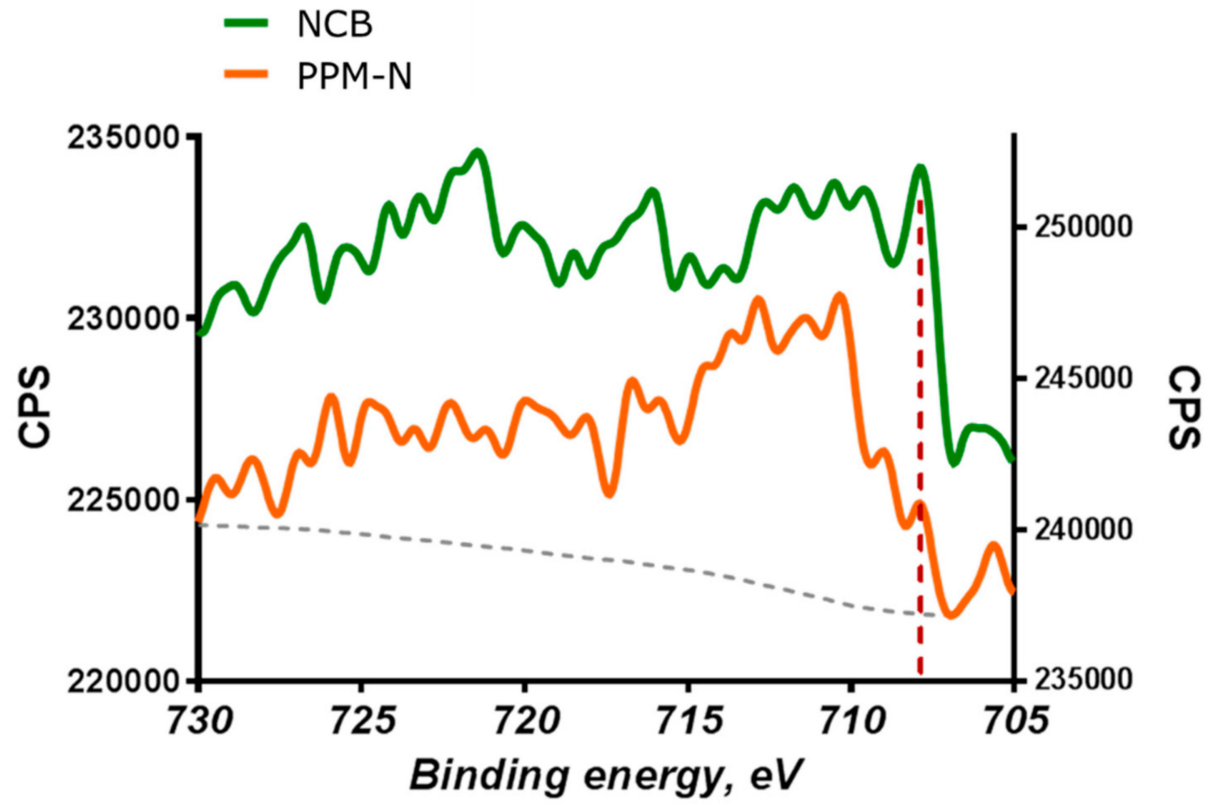

Figure 5. Fe2p HAXPES spectra of NCB and PPM-N. The dot line represents binding energy of metallic Fe: $707 \mathrm{eV}$.

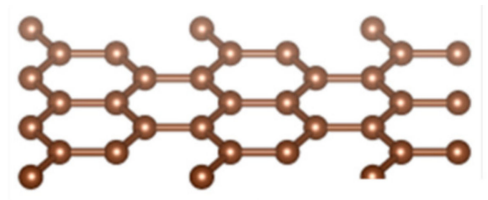

\section{Graphene}

(4) $+2.39 \mathrm{eV}$

(5) $+2.20 \mathrm{eV}$

(7) $+2.86 \mathrm{eV}$

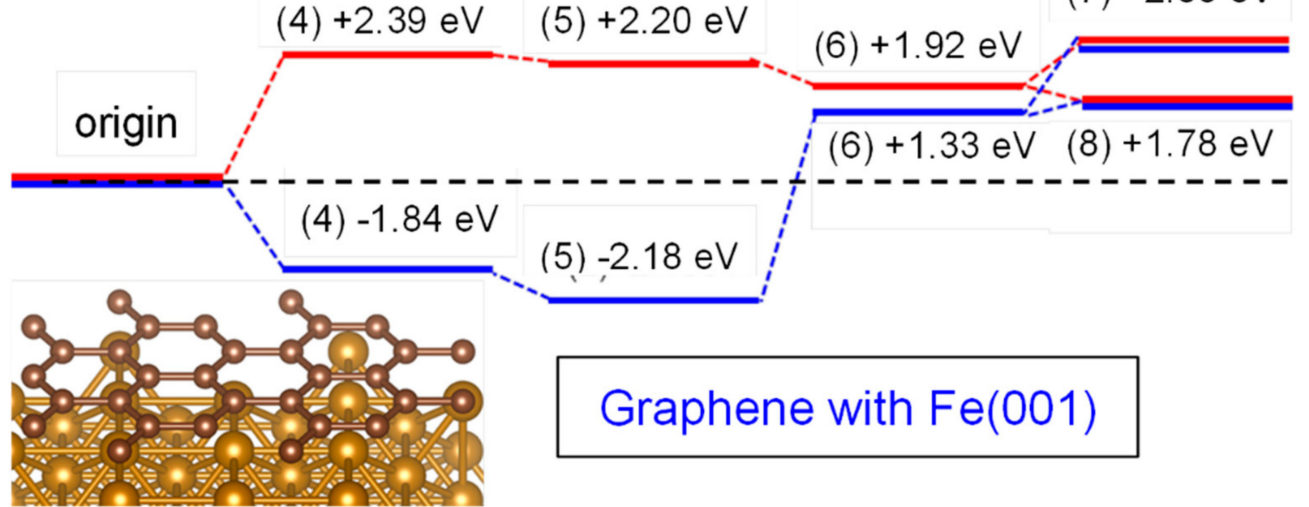

Figure 6. The energy diagrams for the reactions from $\mathrm{O}_{2}$ adsorption to generate $\mathrm{HO}_{2}{ }^{-}$or $\mathrm{OH}^{-}$.

On the other hand, there is no energy barrier in case of graphene with $\mathrm{Fe}(001)$, just requiring endothermic energy to generate $\mathrm{HO}_{2}{ }^{-}:+1.78 \mathrm{eV} / \mathrm{OH}^{-}:+2.86 \mathrm{eV}$. Moreover, $\mathrm{O}_{2}$ and $\mathrm{H}_{2} \mathrm{O}$ adsorption energy: $-2.18 \mathrm{eV}$ is available on graphene with $\mathrm{Fe}(001)$. This indicates that endothermic energy required for the process from $\mathrm{O}_{2}$ to $\mathrm{HO}_{2}{ }^{-}$is given by another $\mathrm{O}_{2}$ and $\mathrm{H}_{2} \mathrm{O}$ adsorption. From these 
results, it is confirmed that $\mathrm{Fe}$ metallic particle substrate enhanced $\mathrm{HO}_{2}{ }^{-}$generation. To reveal this mechanism, the investigations of the density of state (DOS) of graphene without/with Fe(001) were done. The comparison of DOS is shown in Figure 7.
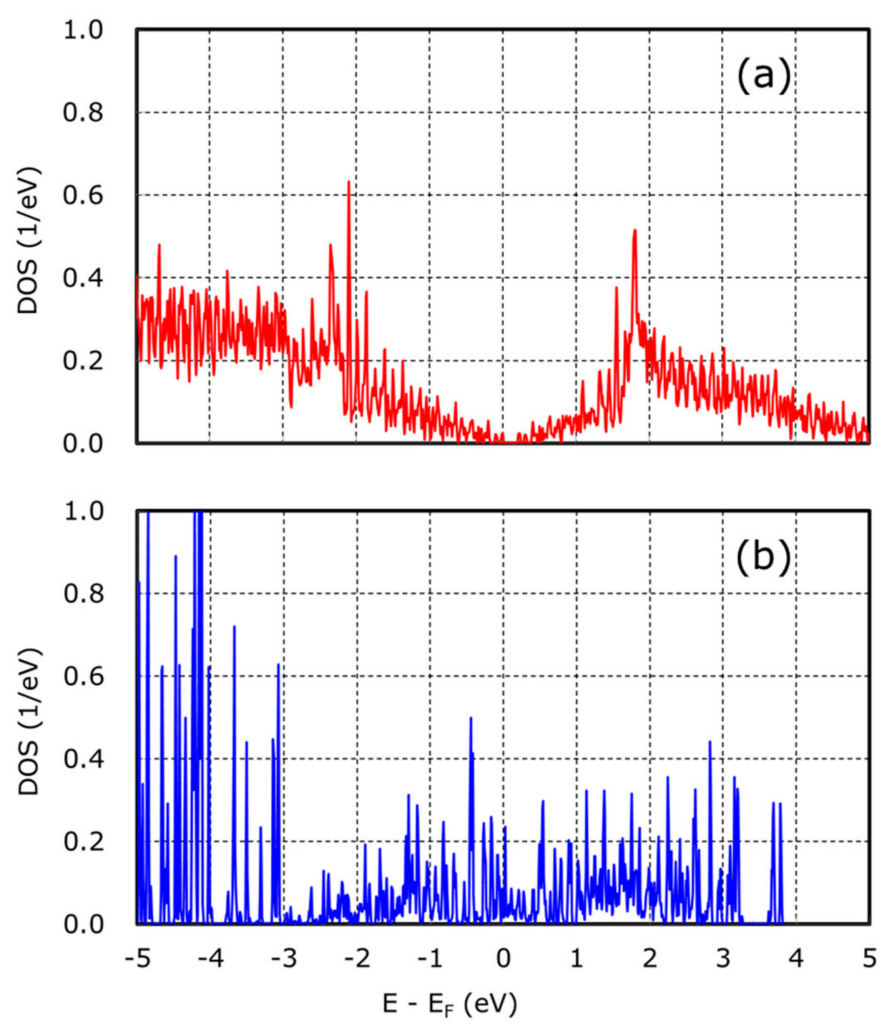

Figure 7. DOS of (a) graphene, and (b) graphene with $\mathrm{Fe}(001)$.

Figure 7a shows that graphene without $\mathrm{Fe}(001)$ had a band gap around Fermi energy, indicating semiconductive character. On the other hands, Figure $7 \mathrm{~b}$ shows that graphene with $\mathrm{Fe}(001)$ had an electric state around Fermi energy, indicating conductive character. Therefore, charge transfer from graphene to adsorbed $\mathrm{O}_{2}$ was more favorable on graphene with $\mathrm{Fe}(001)$ rather than graphene without $\mathrm{Fe}(001)$. We conclude that this difference of DOS affected required energy for $\mathrm{O}_{2}$ adsorption (energy barrier for $\mathrm{HO}_{2}{ }^{-}$generation).

From the ex-situ XAFS, RRDE, STEM, HAXPES and theoretical studies, we confirmed that Fe metallic particles enhance $\mathrm{HO}_{2}{ }^{-}$generation. To design reactive $\mathrm{Fe}-\mathrm{N}-\mathrm{C}$ catalysts, the role and active site of the other type of Fe structure present: $\mathrm{Fe}-\mathrm{N}_{\mathrm{x}}$ should be investigated. To identify the detail of $\mathrm{Fe}-\mathrm{N}_{\mathrm{x}}$ structures and reveal the relationship between Fe- $\mathrm{N}_{\mathrm{x}}$ structure and catalytic activity, Mößbauer measurements were done. Figure 8 and Table 4 show the results. 

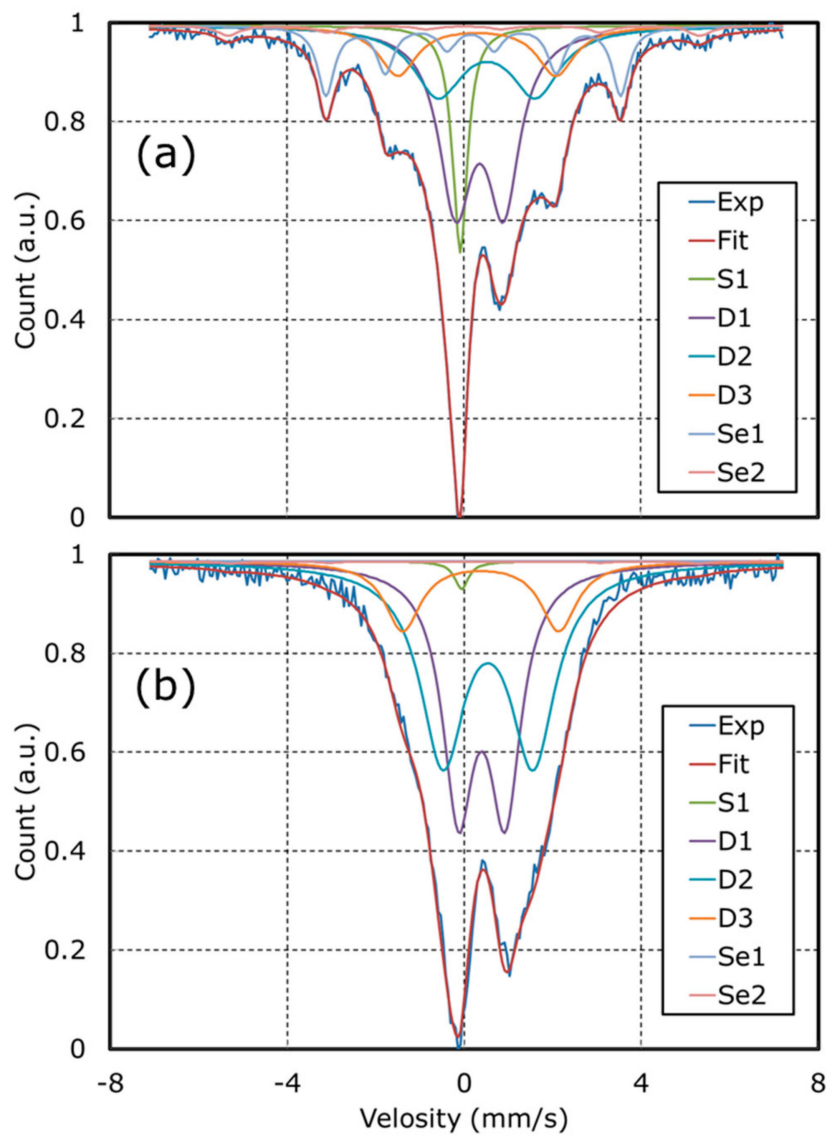

Figure 8. Deconvoluted Mößbauer spectra of (a) NCB and (b) PPM-N.

Table 4. Difference of components of the Fe-N-C electrocatalysts by Mößbauer spectroscopy.

\begin{tabular}{ccccccc}
\hline Catalyst & S1 $(\boldsymbol{\gamma}$-Fe $)$ & Se1 $(\mathbf{F e C})$ & Se2 $(\boldsymbol{\alpha}$-Fe $)$ & D1 & D2 & D3 \\
\hline NCB & 10.8 & 15.3 & 2.9 & 36.9 & 21.8 & 12.3 \\
NCB-N & 10.0 & 0.0 & 0.7 & 36.1 & 37.0 & 16.2 \\
PPM-N & 1.1 & 0.0 & 0.5 & 39.8 & 45.7 & 12.9 \\
\hline
\end{tabular}

The results of Mößbauer measurements represented good agreement with the results of EXAFS in Figure 1 and HAADF-STEM in Figure 4. The high amount of Fe metallic particles assigned $\gamma$-Fe, FeC and $\alpha$-Fe were detected in NCB and high amount of Fe- $\mathrm{N}_{\mathrm{x}}$ structure assigned D1, D2 and D3 sites were detected in PPM-N as shown in Table 4. Here, D1 was assigned to $\mathrm{Fe}^{\mathrm{II}} \mathrm{N}_{4} / \mathrm{C}$ (low spin), D2 was assigned to $\mathrm{Fe}^{\mathrm{II}} \mathrm{N}_{4}$ (like Fe-Phthalocyanine) and D3 was assigned to $\mathrm{N}-\mathrm{Fe}^{\mathrm{II}} \mathrm{N}_{2+2} / \mathrm{C}$ (high spin) sites, respectively [34,35]. The amount of D2 is in proportion to the catalytic activity (confirmed by kinetic currents, half-wave potential and onset potential in Table 2). From these results, it is hypothesized that D2 enhances ORR occur-ring through Equations (2) and (3). To confirm this hypothesis, in-situ XAFS analysis was done to investigate the change of adsorption structure in ORR.

Figure 9 shows the results of in-situ analysis of EXAFS on NCB and PPM-N, respectively. To discuss the change of coordination number of $\mathrm{Fe}-\mathrm{N}_{\mathrm{x}}$, peak shift at first nearest neighbor peak of Fe around $1.6 \AA$ is plotted in Figure 9. Figure 9 represents that the peak of PPM-N is decreased by the potential shift from $0.25 \mathrm{~V}$ to $-0.9 \mathrm{~V}$ (vs. $\mathrm{Hg} / \mathrm{HgO}$ ). This suggests that adsorbed $\mathrm{O}_{2}$ at the initial state $(0.25 \mathrm{~V}$ vs. $\mathrm{Hg} / \mathrm{HgO})$ on the surface of PPM-N is dissociated and reduced to $\mathrm{OH}^{-}$. 


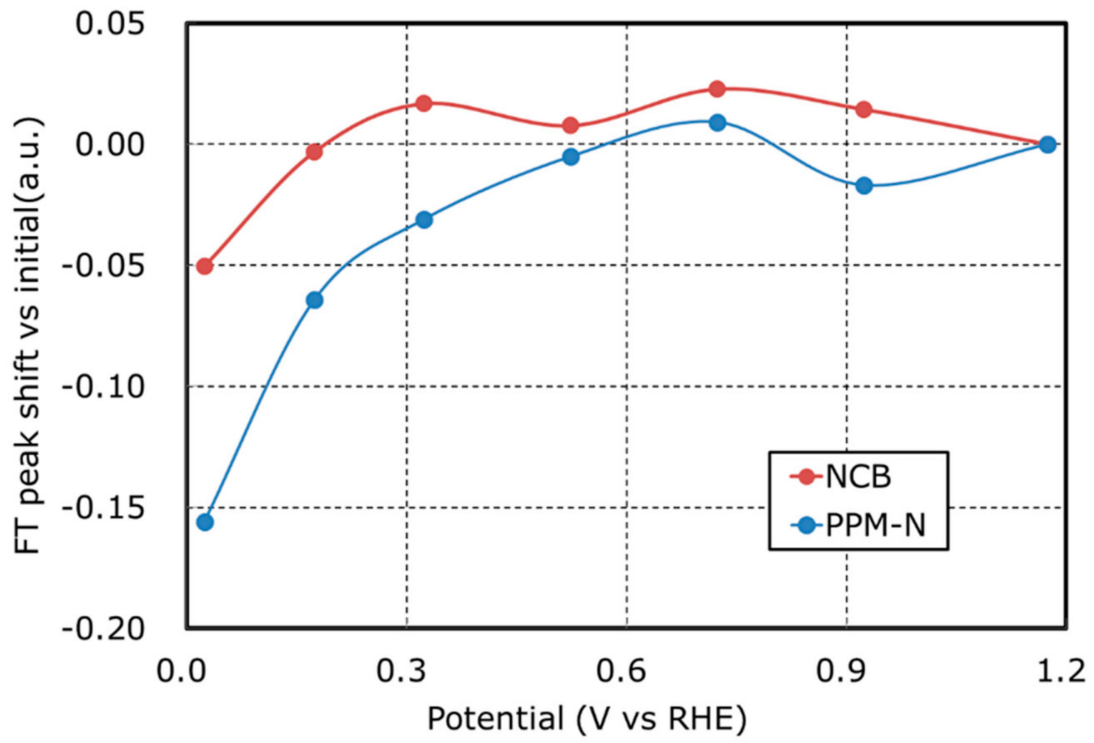

Figure 9. FT peak shift vs initial calculated from in-situ EXAFS data for NCB and PPM-N.

From the results of Mößbauer measurements and in-situ XAFS, we assumed that D2 enhances ORR process. However, in-situ XAFS does not directly suggest a change in the structure of D2 (including D1 and D3). For certification of this assumption, more studies (e.g., DFT calculation for ORR on D1, D2 and D3) are required in future work.

\section{Conclusions}

To reveal the mechanism of $\mathrm{HO}_{2}{ }^{-}$generation from Fe-N-C catalysts, three different Fe-N-C catalysts were analyzed with ex-situ XAFS, STEM, RRDE and DFT calculations. It was revealed that carbon overlay on Fe metallic particles changes the material from a semiconductor to a conductor and enhanced $\mathrm{HO}_{2}{ }^{-}$generation.

Additionally, Mößbauer measurements and in-situ XAFS analysis were performed to better understand the structure of active sites. They suggested that a D2, assigned to $\mathrm{Fe}^{\mathrm{II}} \mathrm{N}_{4}$ (like Fe-Phthalocyanine), structure enhances catalytic activity. It is expected that the research will contribute to the further development of PGM-free electrocatalysts as nanomaterials, leading to widespread popularization of environmentally friendly fuel cells.

Author Contributions: Data curation, K.A. and D.M.; Investigation, T.S., B.H., A.S. and K.T.; Project administration, S.Y. and T.K.; Supervision, P.A., Y.N. and H.T.; Writing—original draft, H.K.; Writing一review \& editing, K.A.

Funding: This work was supported by the CREST, JST (26289254) and DE-EE0000459.

Acknowledgments: The synchrotron radiation experiments were performed at the BL14B2 in the SPring-8 with the approval of the Japan Synchrotron Radiation Research Institute (JASRI) (Proposal No. 2014B1881, 2015A1953, 2015B1889 at BL14B2, 2014B1886 at BL46XU). The Mößbauer measurements were performed with the approval of Nanotechnology Platform project supported by the Ministry of Education, Culture, Sports, Science and Technology. Support for operation and analysis of Mößbauer measurements from K. Mibu (Nagoya Institute of Technology) are gratefully acknowledged. The computation was mainly carried out using the computer facilities at Research Institute for Information Technology, Kyushu University.

Conflicts of Interest: The authors declare no conflicts of interest.

\section{References}

1. Bashyam, R.; Zelenay, P. A class of non-precious metal composite catalysts for fuel cells. Nature 2006, 443, 63-66. [CrossRef] [PubMed]

2. Lefèvre, M.; Proietti, E.; Jaouen, F.; Dodelet, J.P. Iron-Based Catalysts with Improved Oxygen Reduction Activity in Polymer Electrolyte Fuel Cells. Science 2009, 324, 71-74. [CrossRef] [PubMed] 
3. Proietti, E.; Jaouen, F.; Lefèvre, M.; Larouche, N.; Tian, J.; Herranz, J.; Dodelet, J.P. Iron-based cathode catalyst with enhanced power density in polymer electrolyte membrane fuel cells. Nat. Commun. 2011, 2, 416. [CrossRef] [PubMed]

4. Serov, A.; Arthyushkova, K.; Niangar, E.; Wang, C.; Dale, N.; Jaouen, F.; Sougrati, M.T.; Jia, Q.; Mukerjee, S.; Atanassov, P. Nano-structured non-platinum catalysts for automotive fuel cell application. Nano Energy 2015, 16, 293-300. [CrossRef]

5. Hossen, M.M.; Arthyushkova, K.; Atanassov, P.; Serov, A. Synthesis and characterization of high performing Fe-N-C catalyst for oxygen reduction reaction (ORR) in Alkaline Exchange Membrane Fuel Cells. J. Power Sources 2018, 375, 214-221. [CrossRef]

6. Tammeveski, K.; Zagal, J.H. Electrocatalytic oxygen reduction on transition metal macrocyclic complexes for anion exchange membrane fuel cell application. Curr. Opin. Electrochem. 2018, 9, 207-213. [CrossRef]

7. Wang, H.; Yin, F.X.; Chen, B.H.; He, X.B.; Lv, P.L.; Ye, C.Y.; Liu, D.J. ZIF-67 incorporated with carbon derived from pomelo peels: A highly efficient bifunctional catalyst for oxygen reduction/evolution reactions. Appl. Catal. B Environ. 2017, 205, 55-67. [CrossRef]

8. Li, J.; Jaouen, F. Structure and activity of metal-centered coordination sites in pyrolyzed metal-nitrogen-carbon catalysts for the electrochemical reduction of $\mathrm{O}_{2}$. Curr. Opin. Electrochem. 2018, 9, 198-206. [CrossRef]

9. Wang, X.X.; Hwang, S.; Pan, Y.T.; Chen, K.; He, Y.; Karakalos, S.; Zhang, H.; Spendelow, J.S.; Su, D.; Wu, G. Ordered $\mathrm{Pt}_{3} \mathrm{Co}$ Intermetallic Nanoparticles Derived from Metal-Organic Frameworks for Oxygen Reduction. Nano Lett. 2018, 18, 4163-4171. [CrossRef] [PubMed]

10. Jia, Q.; Ramaswamy, N.; Tylus, U.; Strickland, K.; Li, J.; Serov, A.; Artyushkova, K.; Atanassov, P.; Anibal, J.; Gumeci, C.; et al. Spectroscopic insights into the nature of active sites in iron-nitrogen-carbon electrocatalysts for oxygen reduction in acid. Nano Energy 2016, 29, 65-82. [CrossRef]

11. Chung, H.T.; Cullen, D.A.; Higgins, D.; Sneed, B.T.; Holby, E.F.; More, K.L.; Zelenay, P. Direct atomic-level insight into the active sites of a high-performance PGM-free ORR catalyst. Science 2017, 357, 479-484. [CrossRef] [PubMed]

12. Strickland, K.; Miner, E.; Jia, Q.; Tylus, U.; Ramaswamy, N.; Liang, W.; Sougrati, M.T.; Jaouen, F.; Mukerjee, S. Highly active oxygen reduction non-platinum group metal electrocatalyst without direct metal-nitrogen coordination. Nat. Commun. 2015, 6, 7343. [CrossRef] [PubMed]

13. Artyushkova, K.; Serov, A.; Carbonell, S.R.; Atanassov, P. Chemistry of Multitudinous Active Sites for Oxygen Reduction Reaction in Transition Metal-Nitrogen-Carbon Electrocatalysts. J. Phys. Chem. C 2015, 119, 25917-25928. [CrossRef]

14. Chempath, S.; Einsla, B.; Pratt, L.R.; Macomber, C.S.; Boncella, J.M.; Rau, J.A.; Pivovar, B.S. Mechanism of Tetraalkylammonium Headgroup Degradation in Alkaline Fuel Cell Membranes. J. Phys. Chem. C 2008, 112, 3179-3182. [CrossRef]

15. Macomber, C.S.; Boncella, J.M.; Pivovar, B.S.; Rau, J.A. Decomposition pathways of an alkaline fuel cell membrane material component via evolved gas analysis. J. Therm. Anal. Calorim. 2008, 93, 225-229. [CrossRef]

16. Varcoe, J.R.; Slade, R.C.T. Prospects for Alkaline Anion-Exchange Membranes in Low Temperature Fuel Cells. Fuel Cells 2005, 5, 187-200. [CrossRef]

17. Varcoe, J.R.; Slade, R.C.T. An electron-beam-grafted ETFE alkaline anion-exchange membrane in metal-cation-free solid-state alkaline fuel cells. Electrochem. Commun. 2006, 8, 839-843. [CrossRef]

18. Varcoe, J.R.; Slade, R.C.T.; Yee, E.L.H.; Poynton, S.D.; Driscoll, D.J.; Apperley, D.C. Poly(ethylene-co-tetrafluoroethylene)-Derived Radiation-Grafted Anion-Exchange Membrane with Properties Specifically Tailored for Application in Metal-Cation-Free Alkaline Polymer Electrolyte Fuel Cells. Chem. Mater. 2007, 19, 2686-2693. [CrossRef]

19. Danks, T.N.; Slade, R.C.T.; Varcoe, J.R. Comparison of PVDF- and FEP-based radiation-grafted alkaline anion-exchange membranes for use in low temperature portable DMFCs. J. Mater. Chem. 2002, 12, 3371-3373. [CrossRef]

20. Danks, T.N.; Slade, R.C.T.; Varcoe, J.R. Alkaline anion-exchange radiation-grafted membranes for possible electrochemical application in fuel cells. J. Mater. Chem. 2003, 13, 712-721. [CrossRef]

21. Yamada, K.; Asazawa, K.; Yasuda, K.; Ioroi, T.; Tanaka, H.; Miyazaki, Y.; Kobayashi, T. Investigation of PEM type direct hydrazine fuel cell. J. Power Sources 2003, 115, 236-242. [CrossRef] 
22. Asazawa, K.; Yamada, K.; Tanaka, H.; Oka, A.; Taniguchi, M.; Kobayashi, T. A platinum-free zero-carbon-emission easy fuelling direct hydrazine fuel cell for vehicles. Angew. Chem. Int. Ed. 2007, 46, 8024-8027. [CrossRef] [PubMed]

23. Jasinski, R.A. New Fuel Cell Cathode Catalyst. Nature 1964, 201, 1212-1213. [CrossRef]

24. Serov, A.; Min, M.; Chai, G.; Han, S.; Seo, S.J.; Park, Y.; Kim, H.; Kwak, C. Electroreduction of oxygen over iron macrocyclic catalysts for DMFC applications. J. Appl. Electrochem. 2009, 39, 1509-1516. [CrossRef]

25. Sebastian, D.; Serov, A.; Artyushkova, K.; Atanassov, P.; Arico, A.S.; Baglio, V. Performance, methanol tolerance and stability of Fe-aminobenzimidazole derived catalyst for direct methanol fuel cells. J. Power Sources 2016, 319, 235-246. [CrossRef]

26. Janarthanana, R.; Serov, A.; Kishore Pilli, S.; Gamarra, D.A.; Atanassov, P.; Hibbs, M.R.; Herring, A.M. Direct Methanol Anion Exchange Membrane Fuel Cell with a Non-Platinum Group Metal Cathode based on Iron-Aminoantipyrine Catalyst. Electrochim. Acta 2015, 175, 202-208. [CrossRef]

27. Serov, A.; Atryushkova, K.; Andersen, N.I.; Stariha, S.; Atanassov, P. Original Mechanochemical Synthesis of Non-Platinum Group Metals Oxygen Reduction Reaction Catalysts Assisted by Sacrificial Support Method. Electrochim. Acta 2015, 179, 154-160. [CrossRef]

28. Serov, A.; Zulevi, B.; Artyushkova, K.; Atanassov, P.; Zhang, G.; Chenitz, R.; Lefèvree, M.; Dodelet, J.-P.; Sun, S.; Pann, S.; et al. Platinum Group Metal-Free Oxygen Reduction Reaction Electrocatalysts from Fe-N-C Family: Activity, Durability and Manufacturability. In ECS Meetting Abstract; MA2017-02 1498; The Electrochemical Society: National Harbor, MD, USA, 2017.

29. Stone, D.; Whalley, L.K.; Heard, D.E. Tropospheric $\mathrm{OH}$ and $\mathrm{HO}_{2}$ radicals: Field measurements and model comparisons. Chem. Soc. Rev. 2012, 41, 6348-6404. [CrossRef] [PubMed]

30. Serov, A.; Workman, M.J.; Arthyushkova, K.; Atanassov, P.; McCool, G.; McKinney, S.; Romero, H.; Halevi, B.; Stephenson, T. Highly stable precious metal-free cathode catalyst for fuel cell application. J. Power Sources 2016, 327, 557-564. [CrossRef]

31. Stariha, S.; Atryushkova, K.; Workman, M.J.; Serov, A.; Mckinney, S.; Halevi, B.; Atanassov, P. PGM-free Fe-N-C catalysts for oxygen reduction reaction: Catalyst layer design. J. Power Sources 2016, 326, 43-49. [CrossRef]

32. Asazawa, K.; Kishi, H.; Tanaka, H.; Matsumura, D.; Tamura, K.; Nishihata, Y.; Saputro, A.G.; Nakanishi, H.; Kasai, H.; Atryushkova, K.; et al. In Situ XAFS and HAXPES Analysis and Theoretical Study of Cobalt Polypyrrole Incorporated on Carbon (CoPPyC) Oxygen Reduction Reaction Catalysts for Anion-Exchange Membrane Fuel Cells. J. Phys. Chem. C 2014, 118, 25480-25486. [CrossRef]

33. Sakamoto, T.; Kishi, H.; Yamaguchi, S.; Matsumura, D.; Tamura, K.; Hori, A.; Horiuchi, Y.; Serov, A.; Atryushkova, K.; Atanassov, P.; et al. Mechanism Study of Hydrazine Electrooxidation Reaction on Nickel Oxide Surface in Alkaline Electrolyte by In Situ XAFS. J. Electrochem. Soc. 2016, 10, H951-H957. [CrossRef]

34. Kramm, U.I.; Lefèvre, M.; Larouche, N.; Schmeisser, D.; Dodelet, J.P. Correlations between Mass Activity and Physicochemical Properties of Fe/N/C Catalysts for the ORR in PEM Fuel Cell via ${ }^{57} \mathrm{Fe}$ Mössbauer Spectroscopy and Other Techniques. J. Am. Chem. Soc. 2014, 136, 978-985. [CrossRef] [PubMed]

35. Kramm, U.I.; Herranz, J.; Larouche, N.; Arruda, T.M.; Lefèvre, M.; Jaouen, F.; Bogdanoff, P.; Fiechter, S.; Wurmbach, I.A.; Mukerjee, S.; et al. Structure of the catalytic sites in Fe/N/C-catalysts for $\mathrm{O}_{2}$-reduction in PEM fuel cells. Phys. Chem. Chem. Phys. 2012, 14, 11673-11688. [CrossRef] [PubMed]

36. Shi, Z.; Liu, H.; Lee, K.; Dy, E.; Chlistunoff, J.; Blair, M.; Zelenay, P.; Zhang, J.; Liu, J.S. Theoretical Study of Possible Active Site Structures in Cobalt-Polypyrrole Catalysts for Oxygen Reduction Reaction. J. Phys. Chem. C 2011, 115, 16672-16680. [CrossRef]

37. Saputro, A.G.; Kasai, H. Comparative Study on the Catalytic Activity of the TM-N $\mathrm{N}_{2}$ Active Sites (TM = Mn, $\mathrm{Fe}, \mathrm{Co}, \mathrm{Ni}$ ) in the Oxygen Reduction Reaction: Density Functional Theory Study. J. Phys. Soc. Jpn. 2013, 82, 114704-114715. [CrossRef]

38. Stephens, P.J.; Devlin, F.J.; Chabalowski, C.F.; Frisch, M.J. Ab Initio Calculation of Vibrational Absorption and Circular Dichroism Spectra Using Density Functional Force Fields. J. Phys. Chem. 1994, 98, 11623-11627. [CrossRef]

39. Suntivich, J.; Gasteiger, H.A.; Yabuuchi, N.; Nakanishi, H.; Goodenough, J.B.; Horn, Y.S. Design principles for oxygen-reduction activity on perovskite oxide catalysts for fuel cells and metal-air batteries. Nat. Chem. 2011, 3, 546-550. [CrossRef] [PubMed] 
40. Geniès, L.; Faure, R.; Durand, R. Electrochemical reduction of oxygen on platinum nanoparticles in alkaline media. Electrochim. Acta 1998, 44, 1317-1327. [CrossRef]

41. Escano, M.C.S.; Nakanishi, H.; Kasai, H. Spin-polarized density functional theory study of reactivity of diatomic molecule on bimetallic system: The case of $\mathrm{O}_{2}$ dissociative adsorption on $\mathrm{Pt}$ monolayer on $\mathrm{Fe}(001)$. J. Phys. Chem. A 2009, 113, 14302-14307. [CrossRef] [PubMed]

42. Zhang, J. PEM Fuel Cell. Electrocatalysts and Catalyst Layers; Springer Nature Switzerland AG: Basel, Switzerland, 2008; ISBN 978-1-84800-935-6.

(c)

(C) 2018 by the authors. Licensee MDPI, Basel, Switzerland. This article is an open access article distributed under the terms and conditions of the Creative Commons Attribution (CC BY) license (http://creativecommons.org/licenses/by/4.0/). 